
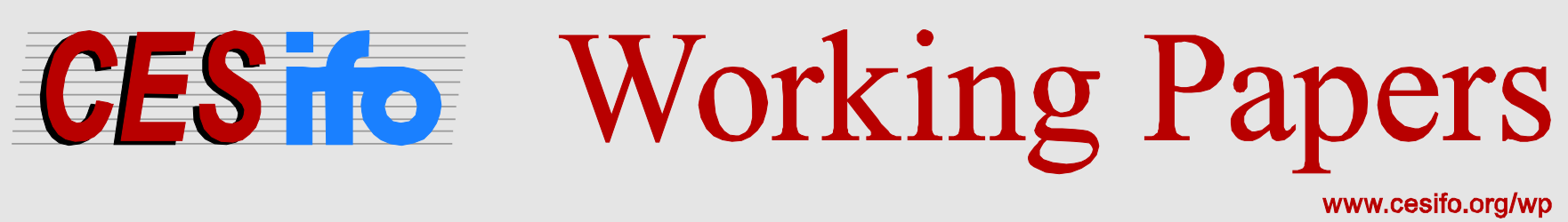

\title{
Student Loans: When is Risk Sharing Desirable?
}

\author{
Bernhard Eckwert \\ Itzhak Zilcha
}

CESIFO WORKING PAPER NO. 5718

CATEGORY 5: ECONOMICS OF EDUCATION

JANUARY 2016

An electronic version of the paper may be downloaded

- from the SSRN website:

- from the RePEc website:

- from the CESifo website: WWW.SSRN.com

www.RePEc.org

www.CESifo-group.org/wp 


\title{
Student Loans: When is Risk Sharing Desirable?
}

\begin{abstract}
In higher education, pure credit market funding leads to underinvestment due to insufficient risk pooling, while pure income-contingent loan funding leads to overinvestment. We analyze whether funding diversity - a market structure in which credit markets coexist alongside income-contingent loan funding - might restore efficiency of the educational investment process. In the absence of government intervention, we find that funding diversity improves pooling of individual income risks and, under some condition, leads to higher social welfare than pure credit market funding. If combined with a policy that restricts access to higher education, funding diversity even achieves full investment efficiency and strictly dominates credit market funding.
\end{abstract}

JEL-codes: D310, H310, I220.

Keywords: higher education, funding diversity, human capital formation.

\author{
Bernhard Eckwert* \\ Bielefeld University \\ Germany - 33501 Bielefeld \\ beckwert@wiwi.uni-bielefeld.de
}

\author{
Itzhak Zilcha \\ Tel Aviv University \\ Israel - 69978 Tel-Aviv \\ izil@post.tau.ac.il
}

*corresponding author

Final Version October 2015

Financial support from the Pinhas Sapir Center for Development, Tel Aviv University, is gratefully acknowledged.We especially wish to acknowledge receiving helpful suggestions from an anonymous referee. 


\section{Introduction}

Higher education financing faces two main problems which may lead to underinvestment in skilled human capital formation. The first problem is due to the peculiarities of human capital which prevent this form of capital from being used as loan collateral. As a consequence, banks are reluctant to provide higher education loans (see, e.g., Galor and Zeira, 1993). The second problem is caused by imperfections in the market for risk bearing. Investment in higher education is risky because students are at least partially ignorant about their abilities and, hence, about the returns on their investments. Yet, financial markets are unlikely to provide adequate pooling or diversification of these risks due to the existence of moral hazard incentives in an agent's acquisition of human capital and in his performance in the labor market.

As a possible response to these market failures the creation of income-contingent loan-repayment programs has been suggested (Friedman, 1962; Nerlove, 1975; Chapman, 2006). Income-contingent loans have the special characteristic that the terms of repayment depend on the borrowers' future incomes: individuals with higher incomes have higher repayment obligations. Such loan contracts not only allow students to pool (part of) their future income risks but can also be used to transfer risks on investment in human capital from borrowers and lenders to third parties. Yet, while income-contingent loans may ease credit constraints and improve the risk allocation, they often also imply significant cross-subsidization between subgroups of students with different future income prospects which may lead to excessive investment in higher education. In fact, students with poor income prospects are more likely to take out education loans under such a scheme than students with good income prospects and, hence, the human capital formation process is characterized by adverse selection (Eckwert and Zilcha, 2012).

Typically, none of these schemes exists in isolation. Our paper therefore concentrates upon the implications of funding diversity: we study the implications of credit funding and income-contingent loans funding when these two schemes coexist and compete against each other for higher education finance. For this purpose, we set up a theoretical framework in which individuals live for two periods. In the 'youth' period, agents obtain education and in the 'working' period they generate incomes based on their human capital and skills. At birth, each individual is randomly 
endowed with some innate ability which becomes fully known only in the working period. Following compulsory schooling in the youth period, each individual receives a (publicly observed) signal which is correlated to his/her true innate ability. The decision whether to acquire higher education after compulsory schooling depends on the financing options available to the agent and on the information conveyed by the signal.

We consider two financing regimes. Under the first regime, the government guarantees access to credit markets for all students who attend higher education. And under the second regime, which is the main focus of our study, income-contingent education finance coexists with competitive credit markets. We find that pure credit market funding leads to underinvestment in higher education. By contrast, funding diversity leads to overinvestment due to adverse selection. Nevertheless, under some condition, funding diversity dominates pure credit market funding in terms of social welfare.

Funding diversity in higher education is plagued by adverse selection in two respects. First, the cross-subsidization within the income-contingent loans program entices students with negative expected net returns on their investments to participate in the program. This misallocation of educational investment raises the financing costs for all participants, because the program is not subsidized by the government and, hence, must break even in equilibrium. Second, the elevated financing costs within the program provide incentives for students with good income prospects to shun the program and turn to the credit market for funding. This effect pushes the financing costs within the program even higher.

The fact that funding diversity alone does not remedy the misallocation of educational investment suggests a role for government policy. This policy would restrict access to higher education to individuals with non-negative expected net returns on their investments, given the signals attained after compulsory schooling. We find that such policy, if combined with funding diversity in higher education, is quite appropriate as it restores efficiency of the educational investment process and, at the same time, mitigates the adverse selection problem within the income-contingent loans program. Moreover, under a policy of restricted access, funding diversity always leads to higher social welfare compared to pure credit market funding. 
Relation to Literature Our work is related to the theoretical literature that analyzes imperfections in financing modes of higher education. One of the earlier contributions is Loury (1981) who analyzes imperfections in the form of exogenous borrowing constraints for education funding. Since then, a number of papers have integrated similar constraints into more extended equilibrium models of higher education. E.g., De Gregorio and Kim (2000) and De Fraja (2002) develop models in which students from better off households are less affected by borrowing constraints which leads to an elitist education provision in equilibrium. Using a Kehoe and Levine (1993) framework, Andolfatto and Gervais (2006) and de la Croix and Michel (2007) analyze the role of endogenous liquidity constraints for educational decisions and human capital formation.

More specificially, our paper is related to the growing literature analyzing various forms of income-contingent loans programs as a means to overcome problems of capital market imperfections, notably Barr (1993) and Chapman (1997, 2006). GarcíaPeñalosa and Wälde (2000) consider alternative self-financing and tax-financed loans programs and compare the efficiency and equity effects with those under a pure loan scheme. Del Rey (2012) applies techniques to student loans that were initially designed for screening in the health insurance market (see also Del Rey and Racionero, 2012). In her set up students are allowed to choose between different sorts of loan contracts. With the exception of Del Rey (2012), all these papers have in common that they analyze and compare the respective funding schemes in isolation.

\section{The Model}

Our economy consists of a production sector, a sector of consumers/workers, and an institutional funding arrangement for higher education. In a first period, the consumers are screened for their unobservable abilities and, based on the screening information, they build up human capital through private investment in higher education. The investment is financed through a loan. The human capital is then used in a second period as input for the production of a consumption good and earns a competitive wage. Finally, the consumers use their wage incomes to repay the loan and to finance consumption. 
Consider a two-period model of a small country in a world where physical capital is internationally mobile while human capital is immobile. By and large, this specification is in line with the empirial observation that the globalization process has promoted international mobility of physical capital far more than international mobility of labor. Production of a homogeneous consumption good is carried out by competitive firms in period 2 according to a constant returns to scale production technology which uses physical capital, $K$, and human capital, $H$, as factors of production. The aggregate production function $F(K, H)$ is concave, homogeneous of degree 1 , and satisfies $F_{K}>0, F_{H}>0, F_{K K}<0, F_{H H}<0$.

International capital mobility in combination with the small country assumption implies that the interest rate, $r$, is exogenously given. Physical capital fully depreciates in the production process. Hence, marginal productivity of aggregate physical capital equals $R:=1+r$. Given the aggregate stock of human capital, $H$, the stock of physical capital $K$ adjusts such that

$$
F_{K}(K, H)=R
$$

is satisfied. Equation (1) and the properties of the production function imply that $K / H$ is determined by the gross international rate of interest $R$. The wage rate which equals the marginal product of human capital, $w=F_{L}(K / H, 1)$, is also determined once $R$ is given.

The consumption sector consists of a continuum of individuals, say, in the interval $[0,1]$. In the first period, following compulsory education, an individual may take out a loan and make a capital investment in higher education in order to acquire additional skills. Thus, the capital investment increases the agent's human capital in the second period when the agent works and earns labor income. Each individual $i$ inelastically supplies $l$ units of labor. The agent's supply of effective labor units is then given by $l h^{i}$ with $h^{i}$ denoting the individual human capital level. His labor income in period 2 is $w l h^{i}$, where $w$ denotes the wage rate (price of one efficiency unit of labor). To ease notation we adopt the normalization $l=1$. Labor income is assumed to be observable by the government (tax authorities), but cannot be observed by private credit institutions. ${ }^{1}$ In the second period, the individual consumes

\footnotetext{
${ }^{1}$ This observability assumption differs from, e.g., De Fraja (2002) who assumes that ability and income are private information.
} 
his net wealth, i.e., $c^{i}=w h^{i}-R$, which is the difference between his labor income and the repayment obligation of the loan, $R$.

All individuals are risk-averse expected utility maximizers with vNM-utility function $u(\tilde{c})$, where $\tilde{c}$ denotes random second period consumption.

Assumption 1 The utility function $u: \mathbb{R}_{+} \rightarrow \mathbb{R}$ is twice differentiable, strictly increasing and concave, and exhibits relative risk aversion less than or equal to 1 , i.e., $-u^{\prime \prime}(c) c / u^{\prime}(c) \leq 1, \forall c>0 .^{2}$

Diversity within the population is generated by random innate ability, which affects an agent's productivity level. Abilities are assigned to individuals by nature at birth, i.e., at the outset of the first period. At this time, however, individual ability is not observable, and is not even known to the agent himself. Human capital of individual $i$ depends on his random innate ability $a^{i}$ and on his private investment in higher education, $x^{i}$. The investment decision is made at date 0 while random innate ability realizes at date 1 .

In order to keep the analytical setup simple, we assume that following his basic education the agent faces a binary investment choice: he may either invest one unit of capital in education, or he may not invest at all. Following a standard modeling procedure in the growth literature, ability affects productivity of the individual only if he becomes 'skilled'. More specificially, we assume that if the individual does not invest, $x^{i}=0$, he remains unskilled and attains a basic human capital level $A>0$ in period 1 . If the agent invests, $x^{i}=1$, then he becomes a skilled worker. In that case, his human capital in period 2 is $A+\tilde{a}^{i}$, where ability $\tilde{a}^{i}$ represents the additional productivity due to higher education. ${ }^{3}$ The random variable $\tilde{a}^{i}$ assumes values in some interval $\mathcal{A}:=\left[a^{1}, a^{2}\right] \subset \mathbb{R}_{++}$.

We denote by $\mu(a)$ the density of agents with ability $a$ and adopt the normalization $\int_{\mathcal{A}} \mu(a) \mathrm{d} a=1$. From the perspective of an individual in period 0 , ability is random as it is the realization of a random variable $\tilde{a}$ with expectation $\bar{a}:=E \tilde{a}$

\footnotetext{
${ }^{2}$ This restriction on individual attitudes towards risk is needed for technical reasons. It ensures that the 'cutoff signal' which separates individuals who join the income-contingent loans program from those who go to the credit market is uniquely determined.

${ }^{3} \mathrm{~A}$ tilde always indicates a random variable. We delete the tilde when referring to a realization of the random variable.
} 
and distribution $\mu(\cdot)$. Yet, there is no aggregate uncertainty in the economy, i.e., the ex post distribution of abilities across the population is exactly $\mu$. Our modeling approach follows the technique suggested in Feldman and Gilles (1985, Proposition 2 ), where uncertainty exists at the individual level but in the aggregate there is no uncertainty. Throughout the paper we assume $\bar{a}>R / w$, so that investment in education is profitable for an individual with average ability.

Each agent receives a publicly observable signal $y \in Y:=[\underline{y}, \bar{y}] \subset \mathbb{R}$ of his ability, $a$, before he makes the investment decision. The signal might be interpreted as a noisy test result which is correlated with the agent's ability. ${ }^{4}$ Real world examples include high school grades and the matriculation examinations used in many countries. Since the tests are noisy, individuals with the same ability, $a$, typically receive different signals. We denote by $\nu_{a}(y)$ the density according to which signals are distributed across agents with ability $a$. Each individual uses the signal as a screening device and forms expectations about his unknown ability in a Bayesian way. The signals are distributed across the entire population according to $\nu(y)=\int_{\mathcal{A}} \nu_{a}(y) \mu(a) \mathrm{d} a$. If $\tilde{a}_{y}$ denotes random ability conditional on the signal $y$, then average ability of all agents in the signal group $y$ is $\bar{a}_{y}:=E\left[\tilde{a}_{y}\right]$.

The human capital of agent $i$ who has received signal $y^{i}$, will be ${ }^{5}$

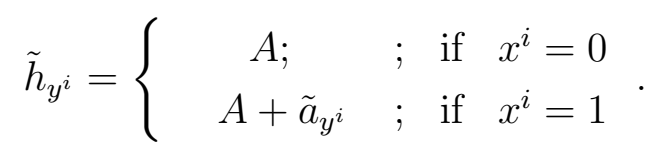

\subsection{Funding Structure and Individual Behavior}

We compare two different market structures for financing loans: competitive credit market, and a structure with coexistence of competitive credit market and incomecontingent loans market. The second structure, which gives individuals a choice between two funding schemes, is the main focus of our analysis.

\footnotetext{
${ }^{4}$ We assume that signals and abilities satisfy the strict Monotone Likelihood Ratio Property (MLRP), i.e., the signals are ordered in such a way that $y^{\prime}>y$ implies that the posterior distribution of ability conditional on $y^{\prime}$ dominates the posterior distribution of ability conditional on $y$ in the first-degree stochastic dominance (see Milgrom, 1981).

${ }^{5}$ All of our results remain valid if $A$ depends on aggregate human capital, $H$, as long as $0 \leq$ $A^{\prime}(H)<1$ is satisfied (see Eckwert and Zilcha, 2014).
} 
The equilibria under both market structures will be evaluated and compared with regard to their social welfare implications. The social planner cannot observe individual preferences, so he assesses social welfare on the basis of observable net income (or consumption) data. More precisely, the social planner's welfare index, $W$, evaluates the distribution of average incomes across the signal groups,

$$
W=\int_{\underline{y}}^{\bar{y}} v\left(\bar{c}_{y}\right) \nu(y) \mathrm{d} y,
$$

where $v: \mathbb{R}_{+} \rightarrow \mathbb{R}$ is a strictly increasing and concave social welfare function, $\bar{c}_{y}:=E[\tilde{c} \mid y]$, and $(\tilde{c} \mid y)$ represents random consumption of an individual with signal $y .{ }^{6}$ Ceteris paribus, higher average consumption in a signal group raises the index; and higher consumption (= income) dispersion across signal groups decreases the index due to the concavity of $v$. The concavity of $v$ thus reflects the inequality aversion of the social planner. Beyond concavity, the specific choice of $v$ has no bearing on the results in this paper.

By construction, the social welfare criterion uses only observable data, namely average incomes in the various signal groups. These data are available to the government and can thus be used for evaluating policy choices. Therefore our comparison of funding schemes and policy options will be based on the social welfare criterion (3).

\subsubsection{Credit Funding Equilibrium (CRE)}

Under this funding structure the government guarantees access to credit markets for all students who attend higher education. Suppose agent $i$ considers to finance his investment via the credit market at the going interest rate $r$, where $R=1+r>0$. The agent will choose $x^{i}=1$, if

$$
E\left[u\left(w A+w \tilde{a}_{y^{i}}-R\right]>u(w A) .\right.
$$

Otherwise he chooses $x^{i}=0$. Due to MLRP (cf. footnote 1) the LHS in (4) is strictly monotone increasing in the signal $y^{i}$. Hence there exists a unique cutoff signal $\hat{y}$ such

\footnotetext{
${ }^{6}$ In our model, all individuals are identical ex ante. Therefore, in equilibrium, agents with the same signal choose identical consumption profiles.
} 
that all individuals with signals larger than or equal to $\hat{y}$ invest in higher education, and individuals with signals lower than $\hat{y}$ do not invest.

The aggregate stock of human capital can then be represented as

$$
H=A+\int_{\hat{y}}^{\bar{y}} \bar{a}_{y} \nu(y) \mathrm{d} y .
$$

In equilibrium, each agent chooses investment in education according to (4), factor markets clear, and aggregate human capital follows the accumulation equation (5).

Definition 1 Given the international gross interest rate $R=1+r$, an equilibrium with credit funding (CRE) consists of a vector $(\hat{y}, w, K, H) \in \mathbb{R}_{+}^{4}, \hat{y} \in[\underline{y}, \bar{y}]$, such that

(i) the cutoff signal, $\hat{y}$, satisfies (4) with equality,

(ii) the aggregate stock of human capital, $H$, satisfies (5),

(iii) the wage and physical capital satisfy $w=F_{L}(K / H, 1)$ and $R=F_{K}(K / H, 1)$.

A CRE always exists and it is unique: for given $R>0$, the second equality in (iii) uniquely determines $K / H$. For given $K / H$, the first equality in (iii) uniquely determines the wage rate $w$. (4) then yields the cutoff signal $\hat{y}$ which is independent of $H$. Finally, aggregate human capital, $H$, is determined by eq. (5).

In a CRE, the economy-wide aggregate investment in education is suboptimally low. To illustrate this fact, we calculate the efficient cutoff signal, $y_{e}$, which maximizes social welfare. In the social welfare optimum, $y_{e}$ separates agents who invest in higher education from those who do not invest. $y_{e}$ maximizes

$$
W(y)=\int_{\underline{y}}^{y} v(w A) \nu\left(y^{\prime}\right) \mathrm{d} y^{\prime}+\int_{y}^{\bar{y}} v\left(w A+w \bar{a}_{y^{\prime}}-R\right) \nu\left(y^{\prime}\right) \mathrm{d} y^{\prime}
$$

and, hence, satisfies

$$
0=W^{\prime}\left(y_{e}\right)=\nu\left(y_{e}\right)\left[v(w A)-v\left(w A+w \bar{a}_{y_{e}}-R\right)\right] \Longleftrightarrow \bar{a}_{y_{e}}=R / w
$$

According to (6), in a social optimum investment in education is efficient in the sense that only those signal groups invest in higher education, for which the expected 
return, $w \bar{a}_{y}$, exceeds the funding cost $R$. This investment rule implies that aggregate consumption is maximized.

From $E\left[w A+w \tilde{a}_{y_{e}}-R\right]=w A$ we conclude

$$
E\left[u\left(w A+w \tilde{a}_{y_{e}}-R\right)\right]<u(w A)
$$

due to risk aversion. Combining (4) and (7) yields $\hat{y}>y_{e}$, i.e., the cutoff signal beyond which agents invest in higher education in a CRE is suboptimally high and, hence, investment is suboptimally low.

Proposition 1 In the CRE, aggregate investment in education is suboptimally low.

Thus, due to risk aversion, underinvestment in higher education results even when credit markets work perfectly (for similar conclusions in a more restricted setting, cf. García-Peñalosa and Wälde, 2000, and Del Rey and Racionero, 2010).

\subsubsection{Equilibrium with Funding Diversity (FDE)}

The inefficiency of educational investment under the credit funding regime is due to the fact that credit funding does not allow individuals to share idiosyncratic ability (hence income) risks. To mitigate the problem of underinvestment, we establish a financial institution (Student Loans Institution, or SLI) that offers income-contingent loan contracts to all individuals who are willing to invest in higher education. The payback obligation of a loan is linked to an individual's future (gross) income: agents with higher incomes (i.e. higher abilities) have higher payback obligations. Clearly, such loan contracts reduce the riskiness of future net income as they provide partial insurance against uncertain income prospects that are due to random ability realizations.

We consider an income-contingent loans (ICL) program that includes all individuals who voluntarily participate and which requires no subsidization from the government. Under the program, all education costs can be covered by the loans. ${ }^{7}$ If

\footnotetext{
${ }^{7}$ Some ICL schemes currently in place fail to cover all education costs. Living expenses, in particular, are sometimes not included.
} 
established, the ICL competes against the regular credit market to attract customers willing to invest in higher education. One important issue to be studied in this section is the characterization of those agents who participate in the ICL program. As it turns out, only individuals with sufficiently unfavorable signals have an incentive to join the program. By contrast, agents with favorable signals tend to prefer the credit market.

A second issue concerns the social desirability of equilibria with funding diversity. Here we find that the competition between the ICL program and the credit market creates an externality which makes the equilibrium less socially desirable. As we shall see, modeling funding diversity requires a more general equilibrium concept in which this externality comes to life.

If agent $i$ decides to invest in higher education and to participate in the ICL, he receives a loan of 1 unit in period 0 with repayment obligation $R a^{i} / a_{0}$ in period $1 .^{8}$ The positive constant $a_{0}$ will be determined in equilibrium such that the ICL breaks even. Assuming that there are no foregone earnings if an agent invests in higher education, the net income from this investment in period 1 is

$$
a^{i}\left[w-\frac{R}{a_{0}}\right]
$$

Note that agent $i$ 's expected payback, $R \bar{a}_{y^{i}} / a_{0}$, is increasing in the signal, i.e., the scheme 'penalizes' agents with high signals.

The ICL-program takes no account of the heterogeneity in ability prospects that is already revealed through the individual signals when investment and borrowing decisions are made. Thus the ICL-program does not just provide insurance, but rather it combines insurance against the unrealized part of ability with cross-subsidization between classes of people in different signal groups: individuals with high signals 'subsidize' those with low signals.

Next we analyze whether income-contingent education finance can coexist with

\footnotetext{
${ }^{8}$ This type of student loan market was studied in Eckwert and Zilcha (2012). Such student loan markets exist in Australia, where repayments are enforced by the tax authorities. Student loan markets also exist in Sweden, the UK and Chile (for more details see Barr and Crawford, 1998; Lleras, 2004). More recently, the US loan system for students has allowed for Income-based Repayment Plan (see, the New York Times, October 25, 2011).
} 
competitive credit markets in the absence of government regulation and, if so, how competition between the two financing schemes affects the efficiency properties of the formation of skilled labor in this economy. Let

$$
\bar{a}\left(y^{\prime}\right):=E\left[\bar{a}_{\tilde{y}} \mid \underline{y} \leq \tilde{y} \leq y^{\prime}\right]
$$

denote average ability of agents in the signal groups between $y$ and $y^{\prime}$. Consider the following arrangement: if all individuals with signals less than or equal to $y^{\prime}$ participate in the ICL-program and all other individuals do not participate, then $a_{0}$ in (8) will be set equal to $\bar{a}\left(y^{\prime}\right)$.

The equality $a_{0}=\bar{a}\left(y^{\prime}\right)$ ensures that the ICL-program just breaks even, if it attracts all individuals with signals less than or equal to $y^{\prime}$.

The net return to investment in education under the ICL-program is then given by

$$
\tilde{a}_{y}\left(w-\frac{R}{\bar{a}\left(y^{\prime}\right)}\right)
$$

for all agents in signal group $y$. Thus, if the net return in (10) is positive for some signal group $y$ then it is positive for all signal groups. Therefore, if the ICL-program does not break down in equilibrium, i.e., if it attracts at least one customer, then all individuals invest in higher education. Some of these individuals, however, may find it optimal to finance their investments via the credit market.

We now investigate which signal groups participate in the ICL-program and which ones choose the credit market. Let

$$
\tilde{c}_{1}(y)=A w+\tilde{a}_{y} w-R
$$

and

$$
\tilde{c}_{2}\left(y ; y^{\prime}\right)=A w+\tilde{a}_{y}\left(w-\frac{R}{\bar{a}\left(y^{\prime}\right)}\right)
$$

where (11) describes random consumption of an agent with signal $y$ if he invests via the credit market; and (12) describes random consumption under the ICL-program. Denote by

$$
V_{1}(y)=E u\left(\tilde{c}_{1}(y)\right) ; \quad V_{2}\left(y ; y^{\prime}\right)=E u\left(\tilde{c}_{2}\left(y, y^{\prime}\right)\right)
$$

the corresponding expected utilities. 
Lemma 1 Suppose $y^{*}$ satisfies

$$
V_{1}\left(y^{*}\right)=V_{2}\left(y^{*} ; y^{*}\right)
$$

Then

$$
V_{1}(y)-V_{2}\left(y ; y^{*}\right)
$$

is strictly increasing in $y$.

Equation (13) implies that individuals in signal group $y^{*}$ are indifferent between investing via the ICL-program and investing via the credit market, if all agents in the signal groups $y \leq y^{*}$ participate in the ICL-program. From Lemma 1 it follows immediately that all agents with signals greater than $y^{*}$ finance their investments via the credit market and all agents with signals smaller than $y^{*}$ participate in the ICL-program. We relegate all proofs to the Appendix.

Definition 2 Given the international gross interest rate $R=1+r$, an equilibrium with funding diversity (FDE, for short) consists of a vector $\left(y^{*}, w, K, H\right) \in \mathbb{R}_{+}^{4}$, $y^{*} \in[\underline{y}, \bar{y}]$, such that

(i) the cutoff signal, $y^{*}$, satisfies $u(A w) \leq V_{2}\left(y^{*}, y^{*}\right)=V_{1}\left(y^{*}\right){ }^{9}$

(ii) the aggregate stock of human capital satisfies $H=A+E \tilde{a}$,

(iii) the wage and physical capital satisfy $w=F_{L}(K / H, 1)$ and $R=F_{K}(K / H, 1)$.

The main difference between definitions 1 and 2 lies in the role of the cutoff signal. In the CRE (Def. 1) the cutoff signal separates individuals who invest in higher education from those who do not invest, while in the FDE (Def. 2) all agents choose to invest in higher education and the cutoff signal separates individuals who seek funds from the credit market from those who participate in the ICL-program.

In (i), the inequality ensures that the ICL-program does not break down, and the equality implies that the credit market co-exists alongside the ICL-program. Note that, given (12), the inequality $u(A w) \leq V_{2}\left(y^{*}, y^{*}\right)$ implies $w \bar{a}\left(y^{*}\right) \geq R$, i.e.,

\footnotetext{
${ }^{9} y^{*}:=\bar{y}$, if $V_{2}(y, y)>V_{1}(y)$ for all $y$.
} 
on average investment in education within the ICL-program is profitable. Moreover, the last inequality in combination with (3) and (13) implies $y^{*}>\hat{y}$. Thus, in the FDE fewer individuals use the credit market than in the CRE. The equality in (ii) holds because in this equilibrium all individuals invest in higher education. In fact, according to Lemma 1, all agents with signals lower than $y^{*}$ join the ICL-program, and all other agents finance their educational investments via the credit market.

If the agents are risk-neutral, then the equality in (i) of Definition 2 is only satisfied for $y^{*}=y$. In that case, no FDE exists, because $y<y_{e}$ has been assumed. Thus, a sufficient amount of risk aversion is necessary for this type of equilibrium to exist. ${ }^{10}$

In a FDE, all individuals are (weakly) better off at the interim stage, i.e., after they have received their signals, than in an equilibrium with credit funding. This follows from the observation that expected utility of individuals with signals $y \geq$ $y^{*}$ stays the same, and expected utility of all other agents increases because they voluntarily choose to participate in the ICL-program rather than using the credit market.

Nevertheless, even though competition between the financing schemes has some merits, the FDE is still inefficient. Inefficiencies are caused by two factors. The first factor consists of an externality, which is caused by the competition between the schemes. The externality is imposed on individuals who participate in the ICLprogram: the more agents go to the credit market, the less favorable are the terms of repayment for agents participating in the ICL-program. Due to this externality, the cutoff signal $y^{*}$ is suboptimally low, i.e., it lies below the socially optimal level.

Proposition 2 In the FDE, the cutoff signal, $y^{*}$, which separates the signal groups that join the ICL-program from the signal groups that use the credit market, is sub-

\footnotetext{
${ }^{10}$ Let $y^{\prime}$ be defined by $\bar{a}\left(y^{\prime}\right) w=R$ which implies $y^{\prime}>y_{e}$. Then a risk sharing equilibrium exists if, as a sufficient condition, individual preferences satisfy the inequalities

$$
\begin{gathered}
u(A w)<E u\left(A w+w \tilde{a}_{y^{\prime}}-R\right) \\
E u\left(A w+w \tilde{a}_{\bar{y}}-\left(\tilde{a}_{\bar{y}} / \bar{a}\right) R\right)>E u\left(A w+w \tilde{a}_{\bar{y}}-R\right) .
\end{gathered}
$$
}


optimally low, i.e.,

$$
\frac{\partial W\left(y^{*}\right)}{\partial y^{*}}>0
$$

According to Proposition 2, the externality from funding competition could be mitigated and social welfare could be raised if some individuals who finance their investment through the credit market would join the ICL-program. Yet, in the absence of government intervention these individuals have no incentive to change their financing decisions.

Second, in an FDE, individuals with very low signals $y<y_{e}$ invest in higher education because they are subsidized by other agents in the ICL-program. Investments of these individuals are inefficient for the economy as a whole because, on average, the returns to these investments fall short of the investment costs; i.e., $w \bar{a}_{y}<R$ for $y<y_{e}$.

Proposition 3 In the FDE, aggregate investment in higher education is suboptimally high.

\section{Funding Structure and Social Welfare}

Under the funding structures considered so far the investment allocation process is inefficient: in the CRE, aggregate investment is suboptimally low while in the FDE aggregate investment is suboptimally high. Moreover, these funding structures lead to different degrees of income inequality across the signal groups. Both income inequality as well as inefficiencies in the investment process have a negative impact on social welfare. In this section we focus on the combined impact of these two sources of welfare losses, i.e., we investigate how the funding structures compare from the perspective of social welfare.

Supposeficiency: individuals in signal groups lower than $y_{e}$ invest in higher education even though in these signal groups the funding cost exceeds the average return to investment. Yet, the FCE has a more unequal income distribution than the ICLE, because the pool of agents who participate in the ICL-program is adversely selected: individuals with high signals and, hence, excellent income prospects don't join the program thereby worsening the terms of loan repayment for agents with lower 
signals who participate in the program. This mechanism reduces social welfare as it increases the spread between incomes in high signal groups and incomes in low signal groups.

\section{Proposition 4}

$$
w \bar{a}-R \geq \int_{\hat{y}}^{\bar{y}}\left(w \bar{a}_{y}-R\right) \nu(y) d y,
$$

i.e., the aggregate net return to investment in education is higher in the FDE than in the CRE. Then social welfare is higher in the FDE than in the CRE.

The investment inefficiency in the FDE (agents with signals less than $y_{e}$ investing in higher education) and, hence, the term on the LHS in (15) is independent of posterior ability risks and of the individuals' attitudes towards those risks. The investment inefficiency in the CRE, by contrast, results from individuals with signals higher than $y_{e}$ but lower than $\hat{y}$ who refuse to invest in higher education because they shy away from the involved risk. This effect is strengthened by both higher posterior ability risk and higher individual risk aversion. The investment inefficiency in the CRE therefore increases and, hence, the term on the RHS in (15) declines with higher posterior ability risk and/or higher individual risk aversion. Thus, Proposition 4 suggests that social welfare is higher in the FDE than in the CRE if either individuals are strongly risk-averse or if the screening information is vague such that the posterior ability risks remain high.

\subsection{Access Restriction to Higher Education}

In the FDE the economy-wide aggregate investment in education is suboptimally high. This overinvestment worsens the terms of loan repayment for individuals who participate in the ICL-program. The problem is intensified as individuals in the highest signal groups turn to the credit market for funding which further reduces the attractiveness of the ICL-program. These inherent sources of inefficiency are caused by the free entry to the ICL-program. They can possibly be mitigated by a simple government policy which restricts access to higher education to individuals 
with signals higher than the efficient threshold level $y_{e} \cdot{ }^{11}$ We now investigate how the equilibria with credit funding and with funding competition compare with regard to social welfare, if such access restriction to higher education is implemented. Note that the access restriction will not be binding in the CRE due to $\hat{y}>y_{e}$ (cf. Proposition 1). Thus, the policy regime interferes only with the FDE but leaves the CRE unaffected.

\subsubsection{Restricted Participation FDE (RP/FDE)}

While in principle funding diversity has positive welfare potential as it offers individuals more financing options, the externality created by the interaction of the two financial instruments is a matter of concern. This raises the question whether the externality can be mitigated through some government regulation. We now examine a regulation that is actually implemented in many countries. The regulation restricts access to higher education based on the individuals' test results.

Suppose the government restricts access to higher education under a system of funding diversity where individuals can choose between participating in the ICLprogram and using the credit market. Such restriction not only prevents agents with poor ability prospects from investing, but also makes the pool of agents who participate in the ICL-program less adversely selected. As a consequence, the ICLprogram might become more attractive to individuals with higher signals thereby raising the cutoff signal $y^{*}$ and mitigating the externality from the competition between the two funding schemes. More formally, define

$$
\tilde{c}_{2}\left(y ; y_{e}, y^{\prime}\right):=A w+\tilde{a}_{y}\left(w-\frac{R}{\bar{a}\left(y_{e}, y^{\prime}\right)}\right) ; \quad \bar{a}\left(y_{e}, y^{\prime}\right):=E\left[\bar{a}_{\tilde{y}} \mid y_{e} \leq \tilde{y} \leq y^{\prime}\right] .
$$

$\tilde{c}_{2}\left(y ; y_{e}, y^{\prime}\right)$ represents consumption of an individual with signal $y$ who participates in the ICL-program, if the ICL-program attracts all individuals with signals in $\left[y_{e}, y^{\prime}\right]$. Note that $\tilde{c}_{2}\left(y ; y_{e}, y^{\prime}\right)>A w$ for all $y^{\prime}>y_{e}$. A restricted participation equilibrium with funding diversity (RP/FDE, for short) and government policy $y_{e}$ consists of a cutoff signal, $y^{\dagger}$, that satisfies $E u\left(\tilde{c}_{2}\left(y^{\dagger} ; y_{e}, y^{\dagger}\right)\right)=V_{1}\left(y^{\dagger}\right) .{ }^{12}$

\footnotetext{
${ }^{11}$ In Israel, such policy exists and is based on the matriculation exams grades at the end of high school.

${ }^{12} y^{\dagger}:=\bar{y}$, if $\operatorname{Eu}\left(\tilde{c}_{2}\left(y ; y_{e}, y\right)\right)>V_{1}(y)$ for all $y \in\left[y_{e}, \bar{y}\right]$.
} 
In such equilibrium, only individuals with signals larger than $y_{e}$ (are allowed to) invest in higher education, hence aggregate consumption is maximized. An agent with signal $y$ participates in the ICL-program if $y \in\left[y_{e}, y^{\dagger}\right]$, and he uses the credit market if $y>y^{\dagger}$.

\subsubsection{Restricted Participation and Social Welfare}

We now compare the RP/FDE and the CRE with respect to the social welfare criterion (3). If the government restricts access to higher education, investment efficiency is restored under funding diversity and, hence, the RP/FDE dominates the CRE in terms of social welfare.

Proposition 5 Social welfare is higher in the RP/FDE than in the CRE.

A policy which restricts access to higher education to signal groups with positive net returns on educational investment eliminates overinvestment under funding diversity. As a consequence, coexistence of credit markets and an ICL-program raises social welfare.

\section{Policy Implications and Conclusion}

Our analysis suggests that government intervention in the higher education sector can be helpful in two ways. First, such intervention may mitigate imperfections in the market for risk bearing which prevent risks on investment in higher education from being pooled in diversified portfolios. In particular, pure credit market funding does not allow individuals to pool their idiosyncratic ability risks which results in aggregate underinvestment in higher education. One important task of the government is therefore the organization of additional higher education finance by means of an income-contingent loans program and its implementation. Such program reduces the risks on investments in human capital through pooling, thereby improving the risk allocation in the economy and enhancing accumulation of human capital.

Second, a funding structure for investment in higher education under which an income-contingent loans program coexists with, and competes against, credit markets has two considerable drawbacks which call for further government intervention. 
On the one hand, such funding structure leads to aggegate overinvestment in human capital; on the other hand, the coexistence of the ICL-program and credit market funding creates an externality which leaves the ICL-program adversely selected thereby worsening the terms of repayment for agents participating in the program. The first drawback can be eliminated, and the second drawback can be mitigated, by a policy which restricts access to higher education to individuals with sufficiently promising ability prospects. Under such regulation, the installation of an ICL-program which competes against the credit market for higher education loans raises social welfare in the economy. In order to be effective, government intervention must therefore combine the provision of income-contingent education loans with access restrictions to higher education.

The incentive mechanisms involved when funding systems compete in higher education are relevant in other areas of economic policy as well. In many countries, for instance, health insurance is provided by a public insurance agency as well as by private insurance companies. The public insurance agency pools health risks across the entire population of insurees while the private insurance companies pool health risks only across individuals in the same signal group, i.e., with similar health reports. The competition between these insurance schemes gives rise to similar mechanisms of risk pooling and adverse selction as those studied here for the higher education sector.

\section{Appendix}

In this Appendix we prove Lemma 1 and propositions 2,4,5 in the main text.

Proof of Lemma 1: By MLRP, the term in (14) is strictly increasing in $y$, if

$$
\rho(a):=u\left(c_{1}(a)\right)-u\left(c_{2}\left(a, y^{*}\right)\right)
$$

is strictly increasing in $a$, where

$$
c_{1}(a):=A w+a w-R ; \quad c_{2}\left(a, y^{*}\right):=A w+a\left[w-\frac{R}{\bar{a}\left(y^{*}\right)}\right] .
$$

Differentiating $\rho(\cdot)$ we get

$$
\rho^{\prime}(a)=w u^{\prime}\left(c_{1}(a)\right)-\left[w-\frac{R}{\bar{a}\left(y^{*}\right)}\right] u^{\prime}\left(c_{2}\left(a, y^{*}\right)\right) .
$$


The RHS of the above equality is trivially positive if $c_{2}\left(a, y^{*}\right) \geq c_{1}(a)$. Let us therefore consider the case $c_{2}\left(a, y^{*}\right)<c_{1}(a)$. The RHS of the last equality can be written as

$\frac{1}{a}\left[c_{1}(a) u^{\prime}\left(c_{1}(a)\right)-c_{2}\left(a, y^{*}\right) u^{\prime}\left(c_{2}\left(a, y^{*}\right)\right)+R u^{\prime}\left(c_{1}(a)\right)+w A\left(u^{\prime}\left(c_{2}\left(a, y^{*}\right)\right)-u^{\prime}\left(c_{1}(a)\right)\right)\right]$.

This expression is positive because $c_{1}(a)>c_{2}\left(a, y^{*}\right)$ and $c u^{\prime}(c)$ is increasing in $c$ by Assumption 1.

Proof of Proposition 2: We need to show that $\partial W\left(y^{*}\right) / \partial y^{*}>0$. Define

$$
\begin{aligned}
c\left(y, y^{*}\right) & :=A w+\bar{a}_{y}\left[w-\frac{R}{\bar{a}\left(y^{*}\right)}\right] \\
c(y) & :=A w+\bar{a}_{y}-R
\end{aligned}
$$

By MLRP, $c\left(y, y^{*}\right)$ and $c(y)$ are both strictly increasing in $y$. Note that

$$
\begin{array}{r}
\int_{\underline{y}}^{y^{*}}\left(w A+\bar{a}_{y}\left[w-\frac{R}{\bar{a}\left(y^{*}\right)}\right]\right) \nu(y) \mathrm{d} y+\int_{y^{*}}^{\bar{y}}\left[w A+\bar{a}_{y} w-R\right] \nu(y) \mathrm{d} y \\
=\int_{\underline{y}}^{\bar{y}}\left[w\left(A+\bar{a}_{y}\right)-R\right] \nu(y) \mathrm{d} y+\underbrace{\int_{y}^{y^{*}}\left[R-\bar{a}_{y} \frac{R}{\bar{a}\left(y^{*}\right)}\right] \nu(y) \mathrm{d} y}_{=0}
\end{array}
$$

Since the RHS of the above equality is independent of $y^{*}$, differentiation with respect to $y^{*}$ yields

$$
\frac{R \bar{a}^{\prime}\left(y^{*}\right)}{\left(\bar{a}\left(y^{*}\right)\right)^{2}} \int_{\underline{y}}^{y^{*}} \bar{a}_{y} \nu(y) \mathrm{d} y=\nu\left(y^{*}\right)\left[c\left(y^{*}\right)-c\left(y^{*}, y^{*}\right)\right]
$$

Now, differentiating

$$
W\left(y^{*}\right)=\int_{\underline{y}}^{y^{*}} v\left(c\left(y, y^{*}\right)\right) \nu(y) \mathrm{d} y+\int_{y^{*}}^{\bar{y}} v(c(y)) \nu(y) \mathrm{d} y
$$

yields

$$
\begin{aligned}
\frac{\partial W\left(y^{*}\right)}{\partial y^{*}} & =\left[v\left(c\left(y^{*}, y^{*}\right)-v\left(c\left(y^{*}\right)\right)\right] \nu\left(y^{*}\right)+\frac{R \bar{a}^{\prime}\left(y^{*}\right)}{\left(\bar{a}\left(y^{*}\right)\right)^{2}} \int_{\underline{y}}^{y^{*}} v^{\prime}\left(c\left(y, y^{*}\right)\right) \bar{a}_{y} \nu(y) \mathrm{d} y\right. \\
& >\left[v\left(c\left(y^{*}, y^{*}\right)-v\left(c\left(y^{*}\right)\right)\right] \nu\left(y^{*}\right)+v^{\prime}\left(c\left(y^{*}, y^{*}\right)\right) \frac{R \bar{a}^{\prime}\left(y^{*}\right)}{\left(\bar{a}\left(y^{*}\right)\right)^{2}} \int_{\underline{y}}^{y^{*}} \bar{a}_{y} \nu(y) \mathrm{d} y\right. \\
& \stackrel{(17)}{=} \nu\left(y^{*}\right)\left\{\left[v\left(c\left(y^{*}, y^{*}\right)-v\left(c\left(y^{*}\right)\right)\right]+v^{\prime}\left(c\left(y^{*}, y^{*}\right)\right)\left[c\left(y^{*}\right)-c\left(y^{*}, y^{*}\right)\right]\right\}\right. \\
& >0
\end{aligned}
$$


The last inequality follows from the concavity of $v(\cdot)$.

Proof of Proposition 4: We prove the proposition by showing that $\bar{c}_{\tilde{y}}^{C R E}$ is a mean decreasing spread of $\bar{c}_{\tilde{y}}^{F D E}$. Average consumption in signal group $y$ is

$$
\bar{c}_{y}^{C R E}=\left\{\begin{array}{cc}
w A ; & ; \text { if } y<\hat{y} \\
w\left(A+\bar{a}_{y}\right)-R & ; \text { if } y \geq \hat{y}
\end{array}\right.
$$

in the CRE, and

$$
\bar{c}_{y}^{F D E}=\left\{\begin{array}{clc}
w A+\bar{a}_{y}\left(w-\frac{R}{\bar{a}\left(y^{*}\right)}\right) & ; \text { if } & y<y^{*} \\
w\left(A+\bar{a}_{y}\right)-R & ; \text { if } & y \geq y^{*}
\end{array}\right.
$$

in the FDE, where $y^{*}>\hat{y}$. From (18) and (19) it follows immediately that

$$
\bar{c}_{y}^{F D E} \stackrel{(\leq)}{>} \bar{c}_{y}^{C R E} \Longleftrightarrow y \stackrel{(\geq)}{<} \hat{y}
$$

i.e., consumption is more dispersed across signal groups in the CRE than in the FDE. In addition, from (15) we conclude

$$
E\left[\bar{c}_{\tilde{y}}^{F D E}\right]-E\left[\bar{c}_{\tilde{y}}^{C R E}\right]=(w \bar{a}-R)-\int_{\hat{y}}^{\bar{y}}\left(w \bar{a}_{y}-R\right) \nu(y) \mathrm{d} y \geq 0 .
$$

Thus, aggregate consumption is higher in the FDE than in the CRE. (20) and (21) together imply that $\bar{c}_{\tilde{y}}^{C R E}$ is a mean decreasing spread of $\bar{c}_{\tilde{y}}^{F D E}$.

Proof of Proposition 5: We prove the proposition by showing that $\bar{c}_{\tilde{y}}^{C R E}$ is a mean-decreasing spread of $\bar{c}_{\tilde{y}}^{R P / F D E}$.

Since in the RP/FDE aggregate consumption is maximized, we conclude

$$
E\left[\bar{c}_{\tilde{y}}^{R P / F D E}\right] \geq E\left[\bar{c}_{\tilde{y}}^{C R E}\right] .
$$

Average consumption in signal group $y$ is given by (18) in the CRE and by

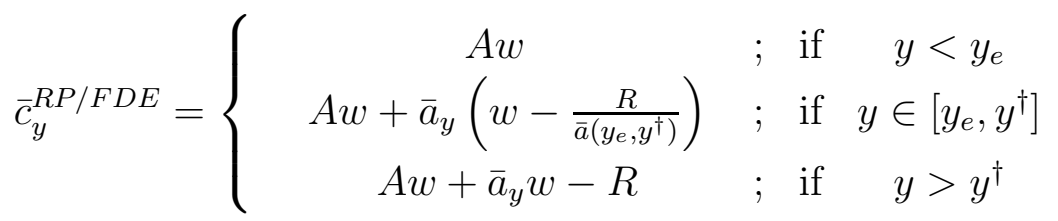


in the RP/FDE. Since $\bar{a}_{y^{\dagger}}>\bar{a}\left(y_{e}, y^{\dagger}\right)$ and $\bar{c}_{y}^{R P / F D E}$ is flatter than $\bar{c}_{y}^{C R E}$ for $y \in\left(\hat{y}, y^{\dagger}\right)$, (18) and (23) imply the existence of $\breve{y} \in\left[\hat{y}, y^{\dagger}\right]$ such that

$$
\bar{c}_{\tilde{y}}^{R P / F D E} \stackrel{(\leq)}{(\geq)} \bar{c}_{\tilde{y}}^{C R E}, \quad \text { if } y \stackrel{(\geq)}{\leq} \breve{y} .
$$

In view of (22) and (24), $\bar{c}_{\tilde{y}}^{C R E}$ is a mean-decreasing spread of $\bar{c}_{\tilde{y}}^{R P / F D E}$.

\section{References}

Andolfatto, D., Gervais, M.: Human Capital Investment and Debt Constraints. Review of Economic Dynamics 9(1), 52-67 (2006).

Barr, N.: Alternative Funding Resources for Higher Education. Economic Journal 103, 718-728 (1993).

Barr, N., Crawford, I.: Funding Higher Education in an Age of Expansion. Education Economics 6(1), 45-70 (1998).

Chapman, B.: Conceptual Issues and the Australian Experience with Income Contingent Charges for Higher Education. Economic Journal 107, 738-751 (1997).

Chapman, B.: Income Contingent Loans for Higher Education: International Reforms, in: E. Hanushek and F. Welch (eds.), Handbook of the Economics of Education, Vol 2, North Holland, 1435-1500 (2006).

De Fraja, G.: The Design of Optimal Education Policies. Review of Economic Studies 69, 437-466 (2002).

De Gregorio, J., Kim, S.-J.: Credit Markets with Differences in Abilities: Education, Distribution and Growth. International Economic Review 41(3), 579-607 (2000).

De La Croix, D., Michel, P.: Education and Growth with Endogenous Debt Constraints. Economic Theory 33, 509-530 (2007). 
Del Rey, E.: Deferring Higher Education Fees without Relying on Contributions from Non-Students. Education Economics 20(5), 510-521 (2012).

Del Rey, E., Racionero, M.: Financing Schemes for Higher Education. European Journal of Political Economy 26(1), 104-113 (2010).

Del Rey, E., Racionero, M.: Choosing the Type of Income-Contingent Loan: RiskSharing versus Risk-Pooling. DP No. 671, Australian National University (2012).

Eckwert, B., Zilcha, I.: Improvement in Information and Private Investment in Education. Journal of Economic Dynamics and Control 34(4), 585-597 (2010).

Eckwert, B., Zilcha, I.: Private Investment in Higher Education: Comparing Alternative Funding Schemes. Economica 79, 76-96 (2012).

Eckwert, B., Zilcha, I.: Sudent Loans: When is Risk Sharing Desirable? Working Paper, Tel Aviv University and Bielefeld University (2014).

Feldman, M., Gilles, C.: An Expository Note on Individual Risk without Aggregate Uncertainty. Journal of Economic Theory 35, 26-32 (1985).

Friedman, M.: Capitalism and Freedom. Chicago: University of Chicago Press (1962).

Galor, O., Zeira, I.: Income Distribution and Macroeconomis. Review of Economic Studies 60, 35-52 (1993).

García-Peñalosa, C., Wälde, K.: Efficiency and Equity Effects of Subsidies to Higher Education. Oxford Economic Papers 52, 702-722 (2000).

Kehoe, T., Levine, D.: Debt-Constrained Asset Markets. Review of Economic Studies 60(4), 865-888 (1993).

Lleras, M.P.: Investing in Human Capital. Cambridge University Press: Cambridge, UK (2004).

Loury, G.: Intergenerational Transfers and the Distribution of Earnings. Econometrica 49(4), 843-867 (1981). 
Milgrom, P. R.: Good News and Bad News: Representation Theorems and Applications. Bell Journal of Economics 12, 380-391 (1981).

Nerlove, M.: Some Problems in the Use of Income-contingent Loans for the Finance of Higher Education. The Journal of Political Economy 83(1), 157-184 (1975). 